\title{
Perceptions of clinical competence among nurse pregraduates: Do different types of nursing programs make a difference?
}

\author{
Ching-Yu Cheng, Shwu-Ru Liou \\ School of Nursing, Chang Gung University of Science and Technology at Chia-Yi Campus, Chi-Yi, Taiwan \\ Correspondence: Shwu-Ru Liou. Address: Chang Gung University of Science and Technology at Chia-Yi Campus No.2, \\ Chiapu Rd. West Sec. Putz City, Chia-Yi, 613, Taiwan. Email: srliou5022@gmail.com.
}

Received: April 20, 2013

Accepted: May 5, 2013

Online Published: June 26, 2013

DOI : 10.5430/jnep.v3n9p139

URL: http://dx.doi.org/10.5430/jnep.v3n9p139

\begin{abstract}
Background: New graduate nurses' competence rarely meets the rigorous expectations of clinical settings. Researchers suggest that competency validation before graduation can shorten the length of clinical orientations for graduate nurses after they enter the workforce. The purpose of this study was to explore the difference in clinical competence between students in different types of nursing programs and to identify skills that need to be reinforced.

Methods: This longitudinal study included 461 students from three different nursing programs: a four-year regular nursing program and a two-year RN-BSN program in day school and night school. A total of 478 students were invited to participate, and 440 students completed and returned questionnaires either at one year before or at the time of graduation with a total response rate of $92.05 \%$.

Results: At the time of graduation, students in all three nursing programs perceived low competence in overall clinical skills. Students in a two-year RN-BSN night school perceived significantly lower competence than students in two other types of nursing programs. Nurse students' general performance skills and advanced nursing skills need to be reinforced before graduation.

Conclusions: More opportunities for students' involvement in case-based studies to cultivate their ability to integrate their knowledge and skills and more accumulated hours in deliberate practice with external sources such as electronic resources, training facilities and skill consultation on performance are recommended to enhance students' clinical competence.
\end{abstract}

\section{Key words}

Nurse pregraduates, Professional nursing behaviour, Core nursing skills, Advanced nursing skills

\section{I ntroduction}

Faced with the global problem of hospital staffing shortages, healthcare administrators expect new graduate nurses to function independently as quickly as possible in order to help overcome deficiencies in manpower. However, researchers have reported that new graduate nurses lack adequate levels of competence that are needed in the real world of clinical nursing practice to meet the ever-increasing demands in today's complicated healthcare environment ${ }^{[1-3]}$. 
Study results have shown that new graduate nurses' clinical competence does not meet expected levels of abilities needed in clinical settings. In one study, only $10.4 \%$ of hospital nurse executives agreed that new graduate nurses are fully prepared to provide safe and effective care in the hospital setting ${ }^{[4]}$. In the same study, only $25 \%$ of nurse leaders were fully satisfied with new graduate nurses' performance at the entry time of their jobs. In addition, researchers reported that nursing educators, new graduate nurses and healthcare administrators in clinical settings perceive a profound gap in the clinical performance of new graduate nurses ${ }^{[5-7]}$. Results from a qualitative study revealed that, from the students' perspective, concerns about becoming a nurse emerged as an important factor related to their clinical competence. In the study, nurse students identified nurse clinical competency as one of the three important motivating factors for them throughout their nursing education ${ }^{[8]}$. In addition, students reported that they would feel more confident if they were more competent in nursing skills ${ }^{[9,10]}$.

\section{Background}

The Joint Commission on Accreditation of Healthcare Organizations emphasizes that competence is an important criterion required from each healthcare provider ${ }^{[11]}$. In addition, the Institute of Medicine stresses that nurse competence plays a significant role in providing patients with safe care ${ }^{[12]}$. Incapable nurses might delay patient treatment in an emergency situation, which can cause serious life-threatening consequences ${ }^{[13]}$. Survey findings published in 2003 revealed that approximately $49 \%$ of newly licensed registered nurses were involved in patient-care errors, with $75 \%$ indicating involvement with medication errors ${ }^{[14]}$. Results from a study that compared clinical competence between new graduate nurses and experienced nurses showed that new graduate nurses were less likely to meet clinical expectations than experienced nurses ${ }^{[15]}$. Incompetent new graduate nurses may cause serious negative patient outcomes. Indeed, the top three reasons for poor patient outcomes are nurses who lack the competence to detect impending patient deterioration, administer appropriate treatment and properly manage complications ${ }^{[16]}$.

The practice of nursing requires good theoretical understanding of nursing knowledge and competence in technical skills, critical thinking, clinical decision-making, and assessment abilities ${ }^{[17,18]}$. However, the definition of competence differs, based on healthcare providers' level of professional education and experience. The Board of Nurse Examiners for the State of Texas and the Texas Board of Vocational Nurse Examiners described competency as effective demonstration of the knowledge, judgment, skills and professional values derived from nursing education by the time of graduation ${ }^{[19]}$. The National Council of State Boards of Nursing characterized competency as capable application of knowledge, interpersonal decision-making and psychomotor skills expected for the practice role ${ }^{[20]}$. The Institute of Medicine asserts that the $21 \mathrm{st}$ century healthcare system should provide clients with safe, effective and patient-oriented care ${ }^{[21]}$. Safe practice is also a concern of new graduate nurses, who identify it as a vital component of competence. They view competence as skilfully performing clinical skills, finding and using resources, applying theoretical knowledge to patient care and managing time and workload ${ }^{[22]}$.

Nurse students' clinical experience in nursing school has a long-term effect on their future competence ${ }^{[18]}$. Many nursing administrators and educators suggest that confirming students' competency before graduation can potentially shorten the length of clinical orientations for new graduate nurses after they enter the workforce ${ }^{[23]}$. Students in different nursing programs have different perceptions about their clinical competence ${ }^{[18,24]}$. In Taiwan, to address the nursing shortage problem, several types of nursing programs are provided. However, in Taiwan, little study has incorporated a measure to evaluate and understand how students in different nursing programs including a four-year regular nursing program, a two-year register nurse to Bachelor of Science in Nursing (RN-BSN) day school program and night school program, perceive their clinical competence before graduation. Therefore, the purpose of our study was to explore the difference in levels of clinical competence between students in the above-mentioned nursing programs and to identify skills that need to be reinforced in different nursing programs while the students are still attending school. The following research questions guided the study: (1) What are the levels of clinical competence reported by the nurse pregraduates? (2) What is the difference in levels of clinical competence between pregraduates attending different types of nursing programs? (3) What components of competence need to be reinforced before the students graduate? (4) What are the changes in nurse students' clinical competence between one year before graduation and at the time of graduation? 


\section{Methods}

\subsection{Design and participants}

We used a longitudinal design for our study, with convenience sampling. Participants were nurse students in a four-year regular nursing program and a two-year RN-BSN program in day school and night school. A total of 478 students were invited to participate in the study: 135 in the four-year regular program, 197 in the two-year RN-BSN day school program and 146 in the two-year RN-BSN night school program. Overall, 197, 97, and 146 students in the two-year RN-BSN day school, four-year regular, and two-year RN-BSN night school program, respectively, returned questionnaires either at one year before or at the time of graduation.

\subsection{I nstruments}

To collect data, we used the Clinical Competence Questionnaire (CCQ), which we developed based on focus group discussions with clinical instructors and senior clinical experts and on literature reviews. The Clinical Competence Questionnaire contains 47-items using a 5-point Likert-type scale with scores ranging from 1 ("do not have a clue") to 5 ("know in theory, competent in practice without any supervision"). A higher score indicates an individual's selfperception of a higher level of clinical competence. Content validity was used to establish the Clinical Competence Questionnaire's initial validity. Factor analysis was applied to test its construct validity. Four factors emerged, consisting of nursing professional behaviours (NPB) and three components of skills: core nursing skills (CNS), general performance (GP) and advanced nursing skills (ANS). The Clinical Competence Questionnaire's concurrent validity was tested and verified that the instrument can adequately predict subsequent events or behaviours ${ }^{[25]}$. Cronbach's $\alpha$ for the entire Clinical Competence Questionnaire was 0.97; Cronbach's $\alpha$ for each of the subscales was 0.95 for nursing professional behaviours, 0.97 for core nursing skills, 0.93 for general performance skills and 0.92 for advanced nursing skills.

\subsection{Procedures}

The study was conducted after obtaining approval from our institution's department, and was accepted and regarded as part of a learning-outcomes evaluation for nursing students before graduation. Data were collected from 2010 to 2011. Packets containing a cover letter, the demographic sheet, the Clinical Competence Questionnaire and a self-addressed stamped envelope were distributed to the students one year before graduation (Time 1) and again at the time of graduation (Time 2). The cover letter provided information about the purposes and procedures of the study, the participants' rights, and the confidentiality and anonymity of data collection and management. Completing and returning the questionnaires indicated the students' agreement to participate in the study.

\subsection{Data analysis}

Data analyses were performed using SPSS software, version 15.0. All tests were 2-sided, and p-values less than 0.05 were considered statistically significant. Descriptive statistics were used to understand participants' demographic characteristics and level of clinical competence. Paired t-test was used to explore the changes in nurse students' competence level Time 1 and Time 2. ANOVA analysis was applied to compare differences in clinical competence between students in three different types of nursing programs.

\section{Results}

\subsection{Descriptive results}

All participants were women and full-time students ranging in ages from 22 to 26 years old. At the time of the investigation, none of the students were employed in any health-related facility. In general, all students had medium-high scores on the entire Clinical Competence Questionnaire and on its subscales at Time 1 and at Time 2. However, their lowest medium-high score at each time period was on the advanced nursing skills subscale of the Clinical Competence 
Questionnaire, compared to the other subscales of nursing professional behaviours, core nursing skills and general performance (see Table 1).

Table 1. Changes in clinical competence between one year before and at the time of graduation

\begin{tabular}{|c|c|c|c|c|c|c|}
\hline & \multicolumn{2}{|l|}{ Time 1} & \multicolumn{2}{|l|}{ Time 2} & & \multirow{2}{*}{$p$} \\
\hline & $\mathbf{M} \pm$ SD & Item $\mathrm{M} \pm \mathrm{SD}$ & $\mathrm{M} \pm \mathrm{SD}$ & Item $\mathrm{M} \pm \mathrm{SD}$ & & \\
\hline \multicolumn{7}{|c|}{ All students } \\
\hline CCQ & $189.65 \pm 26.01$ & $4.04 \pm .55$ & $184.53 \pm 38.30$ & $3.93 \pm .08$ & -2.14 & .03 \\
\hline NPB & $67.30 \pm 8.67$ & $4.21 \pm .54$ & $64.89 \pm 13.86$ & $4.06 \pm .87$ & -2.90 & .004 \\
\hline $\mathrm{CNS}$ & $49.51 \pm 8.09$ & $4.13 \pm .67$ & $48.60 \pm 10.78$ & $4.05 \pm .90$ & -1.33 & .19 \\
\hline GP & $51.69 \pm 7.88$ & $3.98 \pm .61$ & $50.13 \pm 10.64$ & $3.86 \pm .82$ & -2.31 & .02 \\
\hline ANS & $21.11 \pm 4.67$ & $3.52 \pm .78$ & $21.26 \pm 4.84$ & $3.54 \pm .81$ & 0.46 & .64 \\
\hline \multicolumn{7}{|c|}{ Students in four-year regular program } \\
\hline CCQ & $185.54 \pm 20.45$ & $3.95 \pm .44$ & $185.04 \pm 38.72$ & $3.94 \pm .82$ & -.10 & .92 \\
\hline NPB & $67.52 \pm 6.30$ & $4.22 \pm .39$ & $64.53 \pm 13.54$ & $4.03 \pm .85$ & -1.85 & .07 \\
\hline CNS & $47.41 \pm 6.87$ & $3.95 \pm .57$ & $48.43 \pm 10.94$ & $4.04 \pm .91$ & .72 & .48 \\
\hline GP & $51.20 \pm 7.02$ & $3.94 \pm .54$ & $50.99 \pm 10.74$ & $3.92 \pm .83$ & -.15 & .88 \\
\hline ANS & $19.06 \pm 4.40$ & $3.18 \pm .73$ & $21.81 \pm 4.83$ & $3.64 \pm .81$ & 3.62 & $<.001$ \\
\hline \multicolumn{7}{|c|}{ Students in two-year RN-BSN day school program } \\
\hline CCQ & $191.70 \pm 26.02$ & $4.08 \pm .55$ & $192.66 \pm 22.63$ & $4.10 \pm .48$ & .38 & .71 \\
\hline NPB & $68.34 \pm 9.11$ & $4.27 \pm .57$ & $68.69 \pm 8.79$ & $4.29 \pm .55$ & .39 & .70 \\
\hline $\mathrm{CNS}$ & $49.88 \pm 7.95$ & $4.16 \pm .66$ & $51.00 \pm 7.17$ & $4.25 \pm .60$ & 1.43 & .15 \\
\hline GP & $52.14 \pm 8.01$ & $4.01 \pm .62$ & $51.90 \pm 6.88$ & $3.99 \pm .53$ & -.31 & .75 \\
\hline ANS & $21.38 \pm 4.11$ & $3.56 \pm .69$ & $21.30 \pm 3.44$ & $3.55 \pm .57$ & -.21 & .84 \\
\hline \multicolumn{7}{|c|}{ Students in two-year RN-BSN night school program } \\
\hline CCQ & $189.60 \pm 28.55$ & $4.03 \pm .61$ & $167.07 \pm 54.37$ & $3.56 \pm 1.16$ & -3.81 & $<.001$ \\
\hline NPB & $66.46 \pm 8.86$ & $4.15 \pm .55$ & $57.28 \pm 18.73$ & $3.58 \pm 1.17$ & -4.67 & $<.001$ \\
\hline $\mathrm{CNS}$ & $50.06 \pm 8.84$ & $4.18 \pm .74$ & $43.90 \pm 14.38$ & $3.66 \pm 1.20$ & -3.97 & $<.001$ \\
\hline GP & $51.32 \pm 8.33$ & $3.95 \pm .64$ & $45.69 \pm 14.66$ & $3.52 \pm 1.13$ & -3.63 & $<.001$ \\
\hline ANS & $21.80 \pm 5.15$ & $3.63 \pm .86$ & $20.64 \pm 6.60$ & $3.44 \pm 1.10$ & -1.56 & .12 \\
\hline
\end{tabular}

Note. Time 1: one year before graduation; Time 2, at the time of graduation; CCQ: Clinical Competence Questionnaire; NPB: nursing professional behaviours; CNS: core nursing skills; GP: general performance; ANS: advanced nursing skills.

\subsection{Changes in clinical competence between one year before and at the time of graduation}

The combined scores of all students in all of the nursing programs were significantly lower on the entire Clinical Competence Questionnaire and on its subscales of nursing professional behaviours and general performance at Time 2 than at Time 1 (see Table 1). When separately evaluating the competence scores of students from each program, other differences occurred in each group between Time 1 and Time 2. The scores of students in the four-year regular program showed no significant difference on the entire Clinical Competence Questionnaire and on the nursing professional behaviours, core nursing skills and general performance subscales; however, their score on the advanced nursing skills 
subscale was significantly higher. The scores of students in the two-year RN-BSN day school program displayed no significant difference on the entire Clinical Competence Questionnaire and on all of its subscales. Students in the two-year RN-BSN night school program scored significantly lower on the entire Clinical Competence Questionnaire and on the nursing professional behaviours, core nursing skills and general performance subscales; however, their score on the advanced nursing skills subscale showed no significant difference.

\subsection{Comparisons of clinical competence among different nursing programs at the time of graduation}

At the time of graduation, students in the two-year RN-BSN day school program and in the four-year regular program scored significantly higher on the entire Clinical Competence Questionnaire and on the core nursing skills and general performance subscales than students in the two-year RN-BSN night school program (see Table 2). On the nursing professional behaviours, students in the two-year RN-BSN day school program scored significantly higher than students in the four-year regular program, who in turn scored significantly higher than students in the two-year RN-BSN night school program. On the advanced nursing skills, no significant differences were evident in any scores at the time of graduation between the three groups of students in the separate nursing programs.

Table 2. Comparisons of clinical competence among different nursing programs at the time of graduation

\begin{tabular}{|c|c|c|c|c|c|}
\hline & $\mathbf{n}$ & $\mathrm{M} \pm \mathrm{SD}$ & $\mathbf{F}$ & $p$ & Comparison \\
\hline \multicolumn{6}{|l|}{ Clinical Competence Questionnaire } \\
\hline 2-year RN-BSN day school program a & 187 & $192.66 \pm 22.63$ & 13.40 & $<.001$ & $a, b>c$ \\
\hline 4-year regular program $b$ & 89 & $185.04 \pm 38.72$ & & & \\
\hline 2-year RN-BSN night school program c & 100 & $168.88 \pm 53.75$ & & & \\
\hline \multicolumn{6}{|l|}{ Nursing Professional behaviours } \\
\hline 2-year RN-BSN day school program & 195 & $68.69 \pm 8.79$ & 22.30 & $<.001$ & $\mathrm{a}>\mathrm{b}>\mathrm{c}$ \\
\hline 4-year regular program & 91 & $64.53 \pm 13.54$ & & & \\
\hline 2-year RN-BSN night school program & 103 & $58.00 \pm 18.61$ & & & \\
\hline \multicolumn{6}{|l|}{ Core nursing skills } \\
\hline 2-year RN-BSN day school program & 193 & $51.00 \pm 7.17$ & 14.15 & $<.001$ & $a, b>c$ \\
\hline 4-year regular program & 91 & $48.43 \pm 10.94$ & & & \\
\hline 2-year RN-BSN night school program & 102 & $44.22 \pm 14.42$ & & & \\
\hline \multicolumn{6}{|l|}{ General performance } \\
\hline 2-year RN-BSN day school program & 193 & $51.90 \pm 6.88$ & 11.01 & $<.001$ & $a, b>c$ \\
\hline 4-year regular program & 90 & $50.99 \pm 10.74$ & & & \\
\hline 2-year RN-BSN night school program & 103 & $46.07 \pm 14.64$ & & & \\
\hline \multicolumn{6}{|l|}{ Advanced nursing skills } \\
\hline 2-year RN-BSN day school program & 192 & $21.30 \pm 3.44$ & 0.68 & .51 & \\
\hline 4-year regular program & 90 & $21.67 \pm 4.99$ & & & \\
\hline 2-year RN-BSN night school program & 103 & $20.85 \pm 6.64$ & & & \\
\hline
\end{tabular}

\section{Discussion}

The results of this study not only support findings from previous investigations, but also emphasize the need to assess and improve nurse students' clinical competence before they graduate from any type of nursing program. At both testing 
periods (Time 1 and Time 2), students in all three nursing programs exhibited an overall positive level of confidence in their clinical competence. These results are similar to findings from a previous study, in which new graduate nurses generally perceived themselves as competent ${ }^{[18]}$. The students' confidence in their clinical competence, however, may be explained by researchers' reports that some nursing students may overrate or fake confidence when they are asked to evaluate their competence ${ }^{[26,27]}$. Further analyses of the data in our study showed that students in all three programs perceived a higher level of confidence in their nursing professional behaviours and general performance competencies at Time 1 than at Time 2. Similarly, new graduate nurses who initially rated themselves as being comfortable and confident in their clinical competence reported that their confidence level gradually declined ${ }^{[28]}$. Perhaps, as students approach graduation day and move closer to the reality of working in the actual practice setting, they begin to seriously reconsider their clinical competence and doubt their abilities. Many undergraduate nurse students often perceive they lack clinical experience and are unprepared to take on the graduate nurse role ${ }^{[29]}$. Based on the results of our study, nurse pregraduates need more practice experience, especially in advanced nursing skills and general performance skills, to increase their confidence and perceived clinical competence. Special attention is also needed for students in night school programs in order to improve their confidence in almost all nursing skills.

The specific general performance skills measured in our study included skills in assessment, monitoring of patient activity and hygiene, patient and family counselling, charting and documentation and technical skills—all of which have been identified as essential clinical skills for new graduate nurses ${ }^{[28,30,31]}$. Although these general skills are regarded as relatively basic patient care skills, the students in our study, as they approached graduation day, did not have a high level of confidence in performing them. This finding suggests that, before entering the workforce, nurse pregraduates need more opportunities to learn how to integrate and apply their knowledge and to develop their patient assessment and communication skills. Indeed, findings from previous studies not only reveal that new graduate nurses regard general skills such as assessment and charting/documentation as challenging ${ }^{[31]}$, but also demonstrate that new graduate nurses' abilities in integrating and applying knowledge, skills and confident attitudes were not well developed while they were in nursing school ${ }^{[32]}$.

In our study, specific items in the advanced nursing skills subscale included skills in intravenous fluid starts, venipuncture, blood transfusion and chest tube care, which all the nursing students regarded as their weakest technical skills. Similarly, researchers in earlier studies found that new graduate nurses consider these same advanced skills as some of the most challenging procedures to perform in clinical practice ${ }^{[28,31]}$. Students may feel uncomfortable performing these advanced skills because they are invasive procedures, and the students may not be allowed to practice them on patients during their clinical practicum. However, if students do not learn how to properly execute these skills by the time they graduate, they may endanger patients' safety in the practice setting.

Interestingly, the students in our study were confident in performing core nursing skills, which included administering intravenous medications, catheter insertion and care, upper airway/ tracheostomy suction, intravenous drips and wound dressing care. However, results from previous studies showed different results, indicating that new graduate nurses consider these core skills as some of the most difficult to perform ${ }^{[28,31]}$. The reason for this difference in findings was not understood. Perhaps the students in our study realized the importance of being able to safely execute these procedures and, so, practiced them more often in their skill labs.

When comparing levels of perceived competence at the time of graduation, we found that students in the two-year RN-BSN night school program had a lower level of confidence in performing their nursing professional behaviours, core nursing skills and general performance skills than students in the four-year regular program and students in the two-year RN-BSN day school program. Although students in the four-year regular program and students in the two-year RN-BSN day school program exhibited a similar level of perceived competence on the entire Clinical Competence Questionnaire and its subscales of core nursing skills, general performance and advanced nursing skills, students in the four-year program had a lower level of confidence in their nursing professional behaviours skills. These findings are supported by an earlier study in which the self-reported levels of competence in different skills varied among new graduate nurses and the 
type of nursing program they had attended ${ }^{[18]}$. The reason for these differences is likely due to the amount of time the students devoted to practicing their clinical skills. In our study, students in the four-year regular program were required to take skill laboratory courses, which offered more opportunities to practice their skills. In contrast, students in the two-year RN-BSN day and night school programs were not required to take skill laboratory courses because both programs are designed for graduates from a five-year diploma program that already included skills labs. Also, because of the time limitations of attending school at night, students in the night school program may have had even fewer opportunities to practice their skills or discuss problems with their instructors.

\section{Conclusion}

Students in all three nursing programs included in this study had a high level of confidence in their clinical competencies of nursing professional behaviours and core nursing skills; however, they had a low level of confidence in their general performance and advanced nursing skills at Time 1. At the time of their graduation, students in the four-year regular program perceived they had significantly improved their competence in advanced nursing skills over the past year, a result that was not found in students in the two-year RN-BSN day and night school programs. Compared to students in the four-year regular program and students in the two-year RN-BSN day school program, students in the two-year RN-BSN night school had significantly lower levels of confidence in their clinical competencies of nursing professional behaviours, general performance and core nursing skills at the time of their graduation.

Clinical competence is critical for nurse pregraduates before they enter today's complicated healthcare delivery system. Competency validation before graduation can potentially shorten the length of clinical orientations for new graduate nurses after employment ${ }^{[23]}$ and ensure patient safety. However, based on our study's findings, students in all of the nursing programs perceive lower confidence on the entire Clinical Competence Questionnaire at Time 2 than at Time 1 and, in particular, need reinforcement in improving their competence in advanced and general performance skills before graduation. We recommend that all nursing programs, especially two-year RN-BSN programs, provide students with more opportunities in deliberate practice of clinical skills in order to improve pregraduates' technical skills. We also recommend more opportunities for students' involvement in case-based studies in order to cultivate pregraduates' ability to integrate their knowledge, skills and confident attitudes. More accumulated hours in deliberate practice with external sources such as electronic resources, training facilities and skill consultation on performance are also needed to enhance nurse pregraduates' clinical competence ${ }^{[6,33,34]}$. In addition to increased clinical practicum hours, we suggest that nursing programs allow students to remain in the same clinical practicum setting to increase pregraduates' confidence and competence in their clinical skills.

\section{Limitations of the study}

This study included only students enrolled in nursing programs at one university, which limits the generalizability of the results. We recommend additional studies with participants from a variety of nursing schools that have more variabilities. Because our study only explored students' perceptions of their clinical competence level at one year before graduation and at the time of graduation, we also recommend periodic follow up to assess students' changes in competence after graduation, which may help nurse educators understand more about students' needs in the work environment. Despite its limitations, this study provides important and meaningful findings for nurse educators and highlights significant similarities and differences in the perception of clinical competence among nurse pregraduates in different nursing programs.

\section{References}

[1] Marshburn DM, Engelke MK, Swanson MS. Relationships of new nurses' perceptions and measured performance-based clinical competence. The Journal of Continuing Education in Nursing. 2009; 40(9): 426-432. PMid:19754030

http://dx.doi.org/10.3928/00220124-20090824-02

Published by Sciedu Press 
[2] Roberts K, Lockhart R, Spotsman S. A competency transcript to assess and personalize new graduate competency. Journal of Nursing Administration. 2009; 39(1): 19-25. PMid:19104283 http://dx.doi.org/10.1097/NNA.0b013e31818e9d2b

[3] Klein CJ, Fowles ER. An investigation of nursing competence and the competency outcomes performance assessment curricular approach: senior students' self-reported perceptions. Journal of Professional Nursing. 2009; 25(2): 109-121. PMid:19306834 http://dx.doi.org/10.1016/j.profnurs.2008.08.006

[4] Berkow S, Virkstis K, Stewart J, Conway L. Assessing new graduate nurse performance. Journal of Nursing Administration. 2008; 38(11): 468-474. PMid:18997551 http://dx.doi.org/10.1097/01.NNA.0000339477.50219.06

[5] Burns P, Poster E. Competency development in new registered nurse graduates: closing the gap between education and practice. The Journal of Continuing Education in Nursing. 2008; 39(2): 67-73. http://dx.doi.org/10.3928/00220124-20080201-03

[6] Beyea SC, Von Reyn LK, Slattery MJ. A nurse residency program for competence development using human patient simulation. Journal of Nursing Staff Development. 2007; 23(2): 77-82. PMid:17414857 http://dx.doi.org/10.1097/01.NND.0000266613.16434.05

[7] Del Bueno D. A crisis in critical thinking. Nursing Education Perspectives. 2005; 26(5): 278-282. PMid:16295306

[8] Nasrin H, Soroor P, Soodabeh J. Nursing challenges in motivating nursing students through clinical education: a grounded theory study. Nursing Research and Practice. 2012. http://dx.doi.org/10.1155/2012/161359

[9] Mozingo J, Thomas S, Brookes E. Factors associated with perceived competency levels of graduating seniors in a baccalaureate nursing program. Journal of Nursing Education. 1995; 34(3): 115-122. PMid:7745474

[10] Kelly B. The professional self-concepts of nursing undergraduates and their perceptions of influential forces. Journal of Nursing Education. 1992; 31(3): 121-125. PMid:1313087

[11] Kobs A. Competence: the shot heard around the nursing world. Nursing Management 1997; 28(2): 10-13. PMid:9287735 http://dx.doi.org/10.1097/00006247-199702000-00002

[12] Institute of Medicine. Insuring America's Health: Principles and Recommendations. Washington DC, National Academy Press. 2004.

[13] Redfern S, Norman I, Calman L, Watson R, Murrells T. Assessing competence to practice in nursing: a review of the literature. Research Papers in Education. 2002; 17(1): 51-77. http://dx.doi.org/10.1080/02671520110058714

[14] Smith J, Crawford L. Report of findings from the practice and professional issues survey-Spring 2002. 2003. Available from: https://www.ncsbn.org/PPI_spr02_vol7.pdf.

[15] Fero LJ, Witsberger CM, Wesmiller SW, Zullo TG, Hoffman LA. Critical thinking ability of new graduate and experienced nurses. Journal of Advanced Nursing. 2009; 65(1): 139-148. PMid:19032517 http://dx.doi.org/10.1111/j.1365-2648.2008.04834.x

[16] Aiken LH, Clarke SP, Cheung RB, Sloane DM, Silber JH. Educational levels of hospital nurses and surgical patient mortality. Journal of the American Medical Association. 2003; 290(12): 1617-1620. PMid:14506121 http://dx.doi.org/10.1001/jama.290.12.1617

[17] Klein CJ. Linking competency-based assessment to successful clinical practice. Journal of Nursing Education. 2006; 45(9): 379383. PMid:17002086

[18] Greenberger H, Reches H, Riba S. Do new graduates of registered nursing programs in Israel perceive themselves as technically competent? The Journal of Continuing Education in Nursing. 2005; 36(3): 133-140. PMid:16022033

[19] The Board of Nurse Examiners for the State of Texas and Texas Board of Vocational Nurse Examiners. Differentiated entry level competencies of graduates of Texas nursing programs 2002. Available from: http://www.bon.texas.gov/about/pdfs/del-comp.pdf.

[20] Kenward K, Zhong EH. Report of findings from the practice and professional survey-Fall 2004. 2006. Available from: https://www.ncsbn.org/Vol_22_web.pdf.

[21] Institute of Medicine. Crossing the quality chasm: a new health system for the 21 st century. Washington DC, National Academy Press. 2001. Available from: http://www.nap.edu/html/quality_chasm/reportbrief.pdf.

[22] Ramritu P, Barnard A. New nurse graduates' understanding of competence. International Nursing Review. 2001; 48(1): 47-60. http://dx.doi.org/10.1046/j.1466-7657.2001.00048.x

[23] Tanner A. Professional staff education: quantifying costs and outcomes. Journal of Nursing Administration. 2002; 32(2): 91-97. PMid:11984235 http://dx.doi.org/10.1097/00005110-200202000-00007

[24] Koh LC. Teaching technical skills to Project 2000 students. Nursing Standard. 1996; 10(28): 47-49. PMid:8695515

[25] Goodwin L. Changing conceptions of measurement validity: an update on the new standards. Journal of Nursing Education. 2002; 41(3): 100-106. PMid:11939227

[26] Watts WE, Rush K, Wright M. Evaluating first-year nursing students' ability to self-assess psychomotor skills using videotape. Nursing Education Perspectives. 2009; 30(4): 214-219. PMid:19753853

[27] Brown B, O’Mara L, Hunsberger M et al. Professional confidence in baccalaureate nursing students. Nurse Education in Practice. 2003; 3: 163-170. http://dx.doi.org/10.1016/S1471-5953(02)00111-7 
[28] Casey K, Fink R, Krugman M, Propst J. The graduate nurse experience. Journal of Nursing Administration. 2004 ; 34(6): 303-311. PMid:15190226 http://dx.doi.org/10.1097/00005110-200406000-00010

[29] Heslop L, McIntyre M, Ives G. Undergraduate student nurses' expectations and their self-reported preparedness for the graduate year role. Journal of Advanced Nursing. 2001; 36(5): 626-634. PMid:11737494 http://dx.doi.org/10.1046/j.1365-2648.2001.02022.x

[30] Boxer E, Kluge B. Essential clinical skills for beginning registered nurses. Nurse Education Today. 2000; 20 : $327-335$. PMid:10827104 http://dx.doi.org/10.1054/nedt.1999.0415

[31] Fink R, Krugman M, Casey K, Goode C. The graduate nurse experience: quality residency program outcomes. Journal of Nursing Administration. 2008; 38(7/8): 341-348. PMid:18690125 http://dx.doi.org/10.1097/01.NNA.0000323943.82016.48

[32] Smith EL, Cronenwett L, Sherwood G. Current assessments of quality and safety education in nursing. Nursing Outlook. 2007; 55(3): 132-137. PMid:17524800 http://dx.doi.org/10.1016/j.outlook.2007.02.005

[33] Oermann MH, Kardong-Edgren S, Odom-Maryon T et al. Deliberate practice of motor skills in nursing education: CPR as exemplar. Nursing Education Perspectives. 2011; 32(5): 311-315. PMid:22029243 http://dx.doi.org/10.5480/1536-5026-32.5.311

[34] Duvivier RJ, Dalen JV, Muijtjens AM, Moulaert VR, van der Vleuten CP, Scherpbier A. The role of deliberate practice in the acquisition of clinical skills. BMC Medical Education. 2011; 11: 101-108. PMid:22141427

http://dx.doi.org/10.1186/1472-6920-11-101 